\title{
2-(Dichloromethyl)pyrazolo[1,5-a][1,3,5]triazines: synthesis and anticancer activity
}

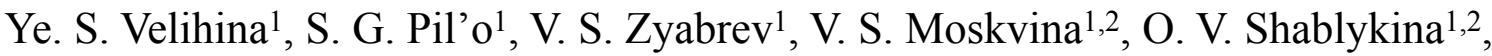 \\ V. S. Brovarets ${ }^{1}$ \\ ${ }^{1}$ V.P. Kukhar Institute of Bioorganic Chemistry and Petrochemistry of the NAS of Ukraine, \\ 1, Murmans'ka Str., Kyiv, Ukraine, 02094 \\ 2 Taras Shevchenko National University of Kyiv \\ 64, Volodymyrska Str., Kyiv, Ukraine, 01601 \\ v.moskvina@gmail.com
}

\begin{abstract}
Aim. Synthesis of a series of 2-(dichloromethyl)pyrazolo[1,5- $a][1,3,5]$ triazines and evaluation in vitro of their anticancer activity against a panel of 60 cell lines derived from nine cancer types, namely leukemia, non-small cell lung cancer, colon cancer, CNS cancer, melanoma, ovarian cancer, renal cancer, prostate cancer, breast cancer. Methods. Organic synthesis; biological tests; spectral methods; statistical methods. Results. In vitro screening of the anticancer activity showed that 5 of 26 tested compounds can effectively inhibit the growth of certain cancer cell lines. Conclusions. New type of $\mathrm{N}$-(2,2-dichloro-1-cyanoethenyl)carboxamides heterocyclization with $1 \mathrm{H}$-pyrazol-5-amines led to the formation of 2-(dichloromethyl)pyrazolo[1,5- $a][1,3,5]$ triazines. Some of these compounds inhibit growth of certain cancer cell lines.
\end{abstract}

Ke y w o r d s: in vitro screening, anticancer activity, heterocyclization, $1 H$-pyrazol-5-amines, pyrazolo[1,5- $a][1,3,5]$ triazines, 2-(dichloromethyl)pyrazolo[1,5- $a][1,3,5]$ triazines.

\section{Introduction}

Organic synthesis plays a vital role in drug discovery, and modern synthetic methods focus on increasing the efficiency of preparing small drug-like molecules which include new drugs and drug candidates and reagents used to explore biological processes [1]. Pyrazolo[1,5-a] $[1,3,5]$ triazines were reported to behave as purine bioisosteres of various cycline-depen- dent kinases inhibitors and as inducers of cell death in a wide variety of human tumor cell lines [2], as hCRF1 receptor antagonists and effective anxiolytic drugs [3], as inhibitors of protein kinase CK2 $[4,5]$, as antimicrobial agents [6], as active inhibition agents of bronchial construction with very low chronotropic effects [7], as anti-proliferative agents for

(C) 2020 Ye. S. Velihina et al.; Published by the Institute of Molecular Biology and Genetics, NAS of Ukraine on behalf of Biopolymers and Cell. This is an Open Access article distributed under the terms of the Creative Commons Attribution License (http://creativecommons.org/licenses/by/4.0/), which permits unrestricted reuse, distribution, and reproduction in any medium, provided the original work is properly cited 
colorectal cancer cell lines [8]. 1H-Pyrazol-5amines (or 5-aminopyrazoles) comprise a class of flexible nitrogen-containing aromatic heterocycles used as privileged organic tools for the construction of diverse fused heterocyclic scaffolds with versatile functionalities [9]. $\mathrm{N}$-(2,2-Dichloro-1-cyanoethenyl)carboxamides are versatile highly reactive electrophilic reagents that are increasingly used in the organic synthesis, in particular in the synthesis of new types of heterocyclic compounds. Pioneering work on the development of cyclocondensation reactions of $N$-(2,2-Dichloro-1cyanoethenyl)carboxamides with $N$-nucleophiles originated in the late 1970's by two research groups of Matsumura and Drach; it was found that these cyclocondensations with various $N$-nucleophiles constitute a facile method for the synthesis of novel 5-amino4-cyanooxazoles [10-14], imidazole [13, 16], pyrazolo[1,5-a]pyrimidine [17], 7,8-dihydroimidazo[1,2-c][1,3] oxazolo[4,5-e]pyrimidine [18], 7,8-dihydroimidazo[1,2-c][1,3]thiazolo[4,5-e]pyrimidine [19], 4,5,7,8-tetrahydroimidazo[1,2-c][1,3]thiazolo[4,5-e][1,3,2]diazaphosphinine [20], and 1,2-dihydro- $2 \lambda^{5}-[1,3]$ oxazolo[5,4- $d][1,3,2]$ diazaphosphinine [21] derivatives. These achievements inspired us to develop an efficient method for the synthesis of new compounds with pyrazolo[1,5-a][1,3,5] triazine moiety. The current study was aimed at the synthesis of new 2-(dichloromethyl) pyrazolo $[1,5-a][1,3,5]$ triazines starting from $1 \mathrm{H}$-pyrazol-5-amines with $\mathrm{N}$-(2,2-dichloro-1cyanoethenyl)carboxamides, and in vitro evaluation of the obtained heterocycles' anticancer activity against a panel of 60 cell lines derived from nine cancer types.

\section{Materials and Methods}

\section{Chemistry}

A series of new pyrazolo[1,5-a][1,3,5]triazine derivatives 3 for in vitro screening for anticancer activity was synthesized starting with $N-(2,2-$ dichloro-1-cyanoethenyl)carboxamides 1 with 1H-pyrazol-5-amines 2 (Scheme 1).

All reagents and solvents used in synthetic procedures were purchased from Aldrich and used as received. The reaction progress was monitored by the TLC method on Silica gel 60 $\mathrm{F}_{254}$ Merck. ${ }^{1} \mathrm{H}(400 \mathrm{MHz})$ and ${ }^{13} \mathrm{C}(100 \mathrm{MHz})$
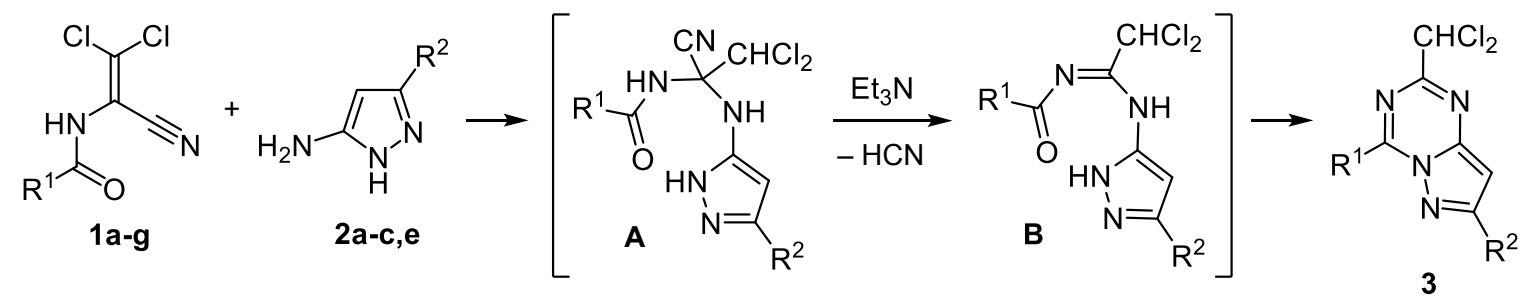

aa $(50 \%)$, ab $(65 \%)$, ac $(72 \%)$, ae $(77 \%)$, ba $(68 \%)$, bb $(75 \%)$, bc $(70 \%)$, be $(76 \%)$, ca $(70 \%)$, cb $(78 \%)$, cc $(70 \%)$, ce $(71 \%)$, da $(80 \%)$, db $(75 \%)$, dc $(68 \%)$, de $(75 \%)$, ea $(75 \%)$, eb $(78 \%)$, ec $(75 \%)$, ee $(79 \%)$, fa $(74 \%)$, fb $(75 \%)$, fc $(67 \%)$, fe $(76 \%)$, gc $(75 \%)$, ge $(72 \%)$,

$\mathrm{R}^{1}, \mathrm{R}^{2}=\mathrm{Me}(\mathbf{a}), \mathrm{Ph}(\mathbf{b}), 4-\mathrm{MeC}_{6} \mathrm{H}_{4}(\mathbf{c}), 4-\mathrm{MeOC}_{6} \mathrm{H}_{4}(\mathbf{d}), 4-\mathrm{FC}_{6} \mathrm{H}_{4}(\mathbf{e}), 4-\mathrm{ClC}_{6} \mathrm{H}_{4}(\mathbf{f}), t-\mathrm{Bu}(\mathbf{g})$

\section{Scheme 1}


NMR spectra of obtained products were recorded at Varian Unityplus 400 spectrometer in DMSO- $d_{6}$ solution with TMS as the internal standard. IR spectra were recorded on a Vertex 70 spectrometer from $\mathrm{KBr}$ pellets. Melting points were measured on a Fisher-Johns instrument.

Chromatomass spectra were recorded on an Agilent 1100 Series high performance liquid chromatograph equipped with a diode matrix with an Agilent LC/MS mass selective detector allowing a fast switching of the positive/negative ionization modes (chemical ionization).

Elemental analyses were performed at the Analytical Laboratory of the V.P. Kukhar Institute of Bioorganic Chemistry and Petrochemistry, NAS of Ukraine, their results were found to be in good agreement $( \pm 0.4 \%)$ with the calculated values.

General procedures of 2-(dichloromethyl) pyrazolo[1,5-a][1,3,5]triazines 3 synthesis. 5-aminopyrazole $(0.01 \mathrm{~mol})$ and $\mathrm{Et}_{3} \mathrm{~N}(1.39 \mathrm{ml}$, $0.01 \mathrm{~mol}$ ) were added to a solution of 2-acylamino-3,3-dichloroacrylonitrile $1(0.01 \mathrm{~mol})$ in $10 \mathrm{ml}$ of THF. The mixture was stirred at room temperature for $24 \mathrm{~h}$, and then heated at $55-60{ }^{\circ} \mathrm{C}$ for $2 \mathrm{~h}$. After solvent evaporation the residue was triturated with water to give a crude product which was dried and recrystallized to obtain yellow or brownish crystals.

Physical and spectral properties of 2-dichloromethyl-4,7-diphenylpyrazolo[1,5-a][1,3,5] triazine (3bb), 2-dichloromethyl-4-phenyl7-(p-tolyl)pyrazolo[1,5-a][1,3,5]triazine (3bc), 2-dichloromethyl-7-methyl-4-(p-tolyl) pyrazolo[1,5-a][1,3,5]triazine (3ca), 2-dichloromethyl-7-phenyl-4-(p-tolyl)-pyrazolo [1,5-a] $[1,3,5]$ triazine $(3 \boldsymbol{c b})$, and 2-dichloromethyl4,7-di(p-tolyl)pyrazolo[1,5-a][1,3,5]triazine (3cc) see [22].
When assigning signals in the ${ }^{1} \mathrm{H}$ and ${ }^{13} \mathrm{C}$ NMR spectra, the atoms of the aryl substituents at position 4 of the heterocycle are designated as $\mathrm{H}^{\prime}$ and $\mathrm{C}^{\prime}$, respectively, the atoms of the aryl substituents in position 7 are designated as $\mathrm{H}^{\prime \prime}$ and $\mathrm{C}^{\prime \prime}$, respectively.

2-Dichloromethyl-4,7-dimethylpyrazolo[1,5-a][1,3,5]triazine (3aa). Mp $108-110^{\circ} \mathrm{C}$ $\left(\mathrm{H}_{2} \mathrm{O}\right) . \mathrm{IR}, \mathrm{v}, \mathrm{cm}^{-1}: 3101,3021,3003,2929$, $1681,1603,1526,1358,1254,843,786,743$, 667. ${ }^{1} \mathrm{H}$ NMR, $\delta, \operatorname{ppm}(J, \mathrm{~Hz}): 2.49(3 \mathrm{H}, \mathrm{s}, \mathrm{Me}-$ 7), 2.91 (3H, s, Me-4), 6.69 (1H, s, H-8), 7.26 $\left(1 \mathrm{H}, \mathrm{s}, \mathrm{CHCl}_{2}\right) \cdot{ }^{13} \mathrm{C} \mathrm{NMR}, \delta$, ppm: 14.5 (Me-7), 19.2 (Me-4), $70.9\left(\mathrm{CHCl}_{2}\right), 97.6$ (C-8), 147.5, 157.2, 158.0, 158.8. MS, m/z $231.1[\mathrm{M}+\mathrm{H}]^{+}$.

2-Dichloromethyl-4-methyl-7-phenylpyrazolo[1,5-a][1,3,5]triazine (3ab). Mp 194$196{ }^{\circ} \mathrm{C}(\mathrm{MeCN}) . \mathrm{IR}, \mathrm{v}, \mathrm{cm}^{-1}: 3012,1606$, $1529,1457,1253,836,787,764,736,688$, 655. ${ }^{1} \mathrm{H}$ NMR, $\delta$, ppm $(J, \mathrm{~Hz}): 3.01(3 \mathrm{H}, \mathrm{s}$, Me-4), $7.23\left(1 \mathrm{H}, \mathrm{s}, \mathrm{H}-8\right.$ or $\left.\mathrm{CHCl}_{2}\right), 7.34(1 \mathrm{H}$, s, $\mathrm{H}-8$ or $\mathrm{CHCl}_{2}$ ), 7.50-7.54 (3H, m, H-3"-5"), $8.09\left(2 \mathrm{H}, \mathrm{d}, J=5.0, \mathrm{H}-2^{\prime \prime}, 6^{\prime \prime}\right) .{ }^{13} \mathrm{C}$ NMR, $\delta$, ppm: 19.2 (Me-4), $70.9\left(\mathrm{CHCl}_{2}\right), 95.0$ (C-8), 126.7, 129.0, 130.1, 131.3, 148.3, 157.5, 157.9, 159.4. MS, m/z $293.0[\mathrm{M}+\mathrm{H}]^{+}$.

2-Dichloromethyl-4-methyl-7-(p-tolyl) pyrazolo[1,5-a][1,3,5]triazine (3ac). Mp 172$174{ }^{\circ} \mathrm{C}(\mathrm{EtOH})$. IR, v, $\mathrm{cm}^{-1}$ : 3001, 1600, 1523, $1449,1255,843,775,657 .{ }^{1} \mathrm{H}$ NMR, $\delta$, ppm $(J, \mathrm{~Hz}): 2.38\left(3 \mathrm{H}, \mathrm{s}, \mathrm{Me}-4^{\prime \prime}\right), 2.98(3 \mathrm{H}, \mathrm{s}$, Me-4), 7.34-7.35 (3H, m, H-8 or $\mathrm{CHCl}_{2}$, H-3", 5"), $7.39\left(1 \mathrm{H}, \mathrm{s}, \mathrm{H}-8\right.$ or $\left.\mathrm{CHCl}_{2}\right), 8.00$ $\left(2 \mathrm{H}, \mathrm{d}, J=8.0, \mathrm{H}-2^{\prime \prime}, 6^{\prime \prime}\right) .{ }^{13} \mathrm{C} \mathrm{NMR}, \delta$, ppm: 19.2 (Me-4), $21.0\left(\mathrm{Me}-44^{\prime \prime}\right), 70.9\left(\mathrm{CHCl}_{2}\right), 94.7$ (C-8), 126.6, 128.5, 129.6, 139.8, 148.3, 157.4, 158.0, 159.3. MS, m/z $307.0[\mathrm{M}+\mathrm{H}]^{+}$.

2-Dichloromethyl-7-(4-fluorophenyl)-4metylpyrazolo[1,5-a][1,3,5]triazine (3ae). Mp 
Ye. S. Velihina, S. G. Pil'o, V. S. Zyabrev et al.

$175-177^{\circ} \mathrm{C}(\mathrm{MeCN}) . \mathrm{IR}, \mathrm{v}, \mathrm{cm}^{-1}: 3009,1612$, 1521, 1449, 1234, 1094, 844, 779, 739, 660. ${ }^{1} \mathrm{H}$ NMR, $\delta$, ppm: 2.98 (3H, s, Me-4), 7.337.42 (4H, m, $\left.\mathrm{CHCl}_{2}, \mathrm{H}-8,3^{\prime \prime}, 5^{\prime \prime}\right), 8.13-8.17$ $\left(2 \mathrm{H}, \mathrm{m}, \mathrm{H}-2^{\prime \prime}, 6^{\prime \prime}\right) .{ }^{13} \mathrm{C} \mathrm{NMR}, \delta$, ppm $(J, \mathrm{~Hz})$ : 19.7 (Me-4), $71.3\left(\mathrm{CHCl}_{2}\right), 95.4(\mathrm{C}-8), 116.5$ (d, $\left.J=21.9, \mathrm{C}-3^{\prime \prime}, 5^{\prime \prime}\right), 128.4$ (d, $\left.J=3.0, \mathrm{C}-1^{\prime \prime}\right)$, 129.5 (d, $\left.J=8.5, \mathrm{C}-2^{\prime \prime}, 6^{\prime \prime}\right), 148.9,157.4,158.1$, $159.9,163.7\left(\mathrm{~d}, J=247.3, \mathrm{C}-4^{\prime \prime}\right)$. MS, m/z $311.0[\mathrm{M}+\mathrm{H}]^{+}$.

2-Dichloromethyl-7-methyl-4phenylpyrazolo[1,5-a][1,3,5]triazine (3ba). Mp 120-122 ${ }^{\circ} \mathrm{C}(\mathrm{EtOH})$. IR, v, cm ${ }^{-1}$ : 3008, $1600,1528,1485,1236,1183,839,783,735$, $686,669,643,530 .{ }^{1} \mathrm{H}$ NMR, $\delta$, ppm $(J, \mathrm{~Hz})$ : $2.52(3 \mathrm{H}, \mathrm{s}, \mathrm{Me}-7), 6.80(1 \mathrm{H}, \mathrm{s}, \mathrm{H}-8), 7.40$ $\left(1 \mathrm{H}, \mathrm{s}, \mathrm{CHCl}_{2}\right), 7.61-7.65$ (3H, m, H-3'-5'), $8.70\left(2 \mathrm{H}, \mathrm{d}, J=8.4, \mathrm{H}-2^{\prime}, 6^{\prime}\right) .{ }^{13} \mathrm{C} \mathrm{NMR}, \delta$, ppm $(J, \mathrm{~Hz}): 14.6(\mathrm{Me}-7), 71.0\left(\mathrm{CHCl}_{2}\right), 97.5(\mathrm{C}-8)$, $128.5,129.5,131.1,133.5,149.9,153.91$, 157.4, 158.7. MS, m/z 293.2 [M+H] $]^{+}$.

2-Dichloromethyl-7-(4-fluorophenyl)-4phenylpyrazolo[1,5-a][1,3,5]triazine (3be). Mp 163-165 ${ }^{\circ} \mathrm{C}(\mathrm{MeCN}+\mathrm{DMF}, 2: 1)$. IR, v, $\mathrm{cm}^{-1}: 3085,2924,1607,1589,1477,1451$, 1226, 840, 795, 781, 663. ${ }^{1} \mathrm{H}$ NMR, $\delta$, ppm $(\mathrm{J}, \mathrm{Hz})$ : 7.30-7.44 (4H, m, $\left.\mathrm{CHCl}_{2}, \mathrm{H}-8,3^{\prime \prime}, 5^{\prime \prime}\right)$, 7.65-7.76 (3H, m, H-3'-5'), 8.11-8.14 (2H, m, $\left.\mathrm{H}-2^{\prime \prime}, 6^{\prime \prime}\right), 8.78\left(2 \mathrm{H}, \mathrm{d}, J=7.2 \mathrm{H}-2^{\prime}, 6^{\prime}\right) .{ }^{13} \mathrm{C}$ NMR, $\delta, \operatorname{ppm}(J, \mathrm{~Hz}): 71.4\left(\mathrm{CHCl}_{2}\right), 95.2$ (C-8), 116.5 (d, $\left.J=21.6, \mathrm{C}-3^{\prime \prime}, 5^{\prime \prime}\right), 128.2$ (d, $\left.J=3.0, \mathrm{C}-1^{\prime \prime}\right), 129.0,129.5(\mathrm{~d}, J=8.5$, C-2",6"), 129.8, 131.7, 134.1, 151.2, 154.7, $157.9,158.1,163.8$ (d, $\left.J=247.5, \mathrm{C}-4^{\prime \prime}\right)$. MS, $\mathrm{m} / \mathrm{z} 371.0[\mathrm{M}+\mathrm{H}]^{+}$.

2-Dichloromethyl-7-(4-fluorophenyl)-4-(ptolyl)pyrazolo [1,5-a][1,3,5]triazine (3ce). Mp 160-162 ${ }^{\circ} \mathrm{C}(\mathrm{MeCN}+\mathrm{DMF}, 2: 1)$. IR, v, $\mathrm{cm}^{-1}$ : $3015,2920,1606,1588,1482,1450,1229$,
$1152,840,785,742,664 .{ }^{1} \mathrm{H}$ NMR, $\delta$, ppm $(J, \mathrm{~Hz}): 2.47\left(3 \mathrm{H}, \mathrm{s}, \mathrm{Me}-4^{\prime}\right), 7.37-7.53(6 \mathrm{H}$, $\left.\mathrm{m}, \mathrm{CHCl}_{2}, \mathrm{H}-8,3^{\prime}, 5^{\prime}, 3^{\prime \prime}, 5^{\prime \prime}\right), 8.18-8.22(2 \mathrm{H}, \mathrm{m}$, $\left.\mathrm{H}-2^{\prime \prime}, 6^{\prime \prime}\right), 8.76\left(2 \mathrm{H}, \mathrm{d}, J=9.6, \mathrm{H}-2^{\prime}, 6^{\prime}\right) .{ }^{13} \mathrm{C}$ NMR, $\delta$, ppm $(J, \mathrm{~Hz}): 21.9$ (Me-4'), 71.5 $\left(\mathrm{CHCl}_{2}\right), 95.2(\mathrm{C}-8), 116.5(\mathrm{~d}, J=21.4$, C-3", $\left.5^{\prime \prime}\right), 127.1,128.4\left(\mathrm{~d}, J=3.0, \mathrm{C}-1^{\prime \prime}\right), 129.6$ (d, $\left.J=8.5, \mathrm{C}-2^{\prime \prime}, 6^{\prime \prime}\right), 129.7,131.8,145.0$, 151.3, 154.7, 157.9, 158.2, 163.9 (d, $J=247.3$, C-4"). MS, m/z $387.2[\mathrm{M}+\mathrm{H}]^{+}$.

2-Dichloromethyl-4-(4-methoxyphenyl)-7methylpyrazolo[1,5-a][1,3,5]triazine (3da). Mp 139-141 ${ }^{\circ} \mathrm{C}$ (MeCN). IR, v, cm ${ }^{-1}: 2993$, 1601, 1527, 1486, 1261, 1180, 1025, 840, 781, 746, 717, 667. ${ }^{1} \mathrm{H}$ NMR, $\delta$, ppm $(J, \mathrm{~Hz}): 2.53$ $(3 \mathrm{H}, \mathrm{s}, \mathrm{Me}-7), 3.91\left(3 \mathrm{H}, \mathrm{s}, \mathrm{MeO}-4^{\prime}\right), 6.75(1 \mathrm{H}$, s, H-8), $7.22\left(2 \mathrm{H}, \mathrm{d}, J=8.8, \mathrm{H}-3^{\prime}, 5^{\prime}\right), 7.35(1 \mathrm{H}$, $\left.\mathrm{s}, \mathrm{CHCl}_{2}\right), 8.87\left(2 \mathrm{H}, \mathrm{d}, J=9.2, \mathrm{H}-2^{\prime}, 6^{\prime}\right) .{ }^{13} \mathrm{C}$ NMR, $\delta$, ppm: 15.1 (Me-7), $56.2\left(\mathrm{MeO}-4^{\prime}\right)$, $71.5\left(\mathrm{CHCl}_{2}\right), 97.7(\mathrm{C}-8), 114.5,121.8,134.0$, $150.6,153.5,157.8,158.8,164.1 . \mathrm{MS}, \mathrm{m} / \mathrm{z}$ $323.0[\mathrm{M}+\mathrm{H}]^{+}$.

2-Dichloromethyl-4-(4-methoxyphenyl)-7phenylpyrazolo[1,5-a][1,3,5]triazine (3db). Mp 138-140 ${ }^{\circ} \mathrm{C}$ (MeCN). IR, v, $\mathrm{cm}^{-1}$ : 2998, $1602,1479,1265,1182,1150,1028,840,764$, 689. ${ }^{1} \mathrm{H}$ NMR, $\delta$, ppm $(J, \mathrm{~Hz}): 3.92(3 \mathrm{H}, \mathrm{s}$, MeO-4'), $7.24\left(2 \mathrm{H}, \mathrm{d}, J=9.2, \mathrm{H}-3^{\prime}, 5^{\prime}\right), 7.40$ $\left(1 \mathrm{H}, \mathrm{s}, \mathrm{H}-8\right.$ or $\left.\mathrm{CHCl}_{2}\right), 7.45(1 \mathrm{H}, \mathrm{s}, \mathrm{H}-8$ or $\left.\mathrm{CHCl}_{2}\right), 7.52-7.54\left(3 \mathrm{H}, \mathrm{m}, \mathrm{H}-3^{\prime \prime}-5^{\prime \prime}\right), 8.14$ $\left(2 \mathrm{H}, \mathrm{d}, J=6.4, \mathrm{H}-2^{\prime \prime}, 6^{\prime \prime}\right), 8.97(2 \mathrm{H}, \mathrm{d}, J=9.2$, $\left.\mathrm{H}-2^{\prime}, 6^{\prime}\right) .{ }^{13} \mathrm{C} \mathrm{NMR}, \delta$, ppm: 56.2 (MeO-4'), $71.6\left(\mathrm{CHCl}_{2}\right), 95.0(\mathrm{C}-8), 114.6,121.7,127.2$, 129.5, 130.6, 131.8, 134.2, 151.3, 153.8, 158.0, 158.6, 164.2. MS, m/z $385.0[\mathrm{M}+\mathrm{H}]^{+}$.

2-Dichloromethyl-4-(4-methoxyphenyl)-7(p-tolyl)pyrazolo[1,5-a][1,3,5]triazine (3dc). Mp 189-191 ${ }^{\circ} \mathrm{C}(\mathrm{MeCN})$. IR, v, $\mathrm{cm}^{-1}: 3014$, 2938, 1598, 1475, 1263, 1182, 1150, 1025, 
844, 787, 746, 664. ${ }^{1} \mathrm{H}$ NMR, $\delta$, ppm $(J, \mathrm{~Hz})$ : 2.39 ( $\left.3 \mathrm{H}, \mathrm{s}, \mathrm{Me}-4^{\prime \prime}\right), 3.94$ ( $\left.3 \mathrm{H}, \mathrm{s}, \mathrm{MeO}-4^{\prime}\right), 7.26$ $\left(2 \mathrm{H}, \mathrm{d}, J=8.8, \mathrm{H}-3^{\prime}, 5^{\prime}\right), 7.34-7.39(4 \mathrm{H}, \mathrm{m}$, $\left.\mathrm{H}-8, \mathrm{CHCl}_{2}, \mathrm{H}-3^{\prime \prime}, 5^{\prime \prime}\right), 8.01(2 \mathrm{H}, \mathrm{d}, J=8.0$, $\left.\mathrm{H}-2^{\prime \prime}, 6^{\prime \prime}\right), 8.98\left(2 \mathrm{H}, \mathrm{d}, J=8.8, \mathrm{H}-2^{\prime}, 6^{\prime}\right) .{ }^{13} \mathrm{C}$ NMR, $\delta$, ppm: 21.5 (Me-4"), 56.3 (MeO-4'), $71.6\left(\mathrm{CHCl}_{2}\right), 94.7(\mathrm{C}-8), 114.7,121.8,127.2$, 129.0, 130.1, 134.2, 140.4, 151.3, 153.8, 158.0, 158.8, 164.2. MS, m/z 399.0 [M+H $]^{+}$.

2-Dichloromethyl-7-(4-fluorophenyl)-4-(4methoxyphenyl)pyrazolo[1,5-a][1,3,5]triazine (3de). Mp 175-177 ${ }^{\circ} \mathrm{C}$ (MeCN+DMF, 2:1). IR, v, $\mathrm{cm}^{-1}$ : 3009, 2923, 1608, 1595, 1481, 1448, 1260, 1228, 1152, 838, 796, 742, 663. ${ }^{1} \mathrm{H}$ NMR, $\delta, \operatorname{ppm}(J, \mathrm{~Hz}): 3.94$ (3H, s, MeO-4'), $7.26\left(2 \mathrm{H}, \mathrm{d}, J=9.0, \mathrm{H}-3^{\prime}, 5^{\prime}\right), 7.38-7.42(3 \mathrm{H}$, m, H-8 or $\left.\mathrm{CHCl}_{2}, \mathrm{H}-3^{\prime \prime}, 5^{\prime \prime}\right), 7.47(1 \mathrm{H}, \mathrm{s}, \mathrm{H}-8$ or $\mathrm{CHCl}_{2}$ ), 8.20-8.22 (2H, m, H-2", $\left.6^{\prime \prime}\right), 8.97$ $\left(2 \mathrm{H}, \mathrm{d}, J=9.0, \mathrm{H}-2^{\prime}, 6^{\prime}\right) .{ }^{13} \mathrm{C} \mathrm{NMR}, \delta, \operatorname{ppm}(J$, $\mathrm{Hz})$ : $56.2\left(\mathrm{MeO}-4^{\prime}\right), 71.6\left(\mathrm{CHCl}_{2}\right), 95.0(\mathrm{C}-8)$, 114.7, 116.5 (d, $\left.J=21.4, \mathrm{C}-3 ", 5^{\prime \prime}\right), 121.7$, $128.4\left(\mathrm{~d}, J=3.0, \mathrm{C}-1^{\prime \prime}\right), 129.6(\mathrm{~d}, J=8.5$, C-2", 6"), 134.2, 151.4, 153.9, 157.7, 158.1, 163.7 (d, $J=247.3$, C-4"), 164.3. MS, m/z $403.0[\mathrm{M}+\mathrm{H}]^{+}$.

2-Dichloromethyl-4-(4-fluorophenyl)-7methylpyrazolo[1,5-a][1,3,5]triazine (3ea). Mp $128-130^{\circ} \mathrm{C}(\mathrm{MeCN})$. IR, v, $\mathrm{cm}^{-1}: 2996,1604$, $1529,1488,1233,1156,1015,842,783,664$, 530. ${ }^{1} \mathrm{H}$ NMR, $\delta$, ppm: $2.51(3 \mathrm{H}, \mathrm{s}, \mathrm{Me}-7), 6.78$ (1H, s, H-8), 7.39 (1H, s, $\left.\mathrm{CHCl}_{2}\right), 7.47-7.51$ ( $\left.2 \mathrm{H}, \mathrm{m}, \mathrm{H}-3^{\prime}, 5^{\prime}\right), 8.81-8.83$ (2H, m, H-2', $\left.6^{\prime}\right)$. ${ }^{13} \mathrm{C}$ NMR, $\delta$, ppm $(J, \mathrm{~Hz}): 15.2$ (Me-7), 71.4 $\left(\mathrm{CHCl}_{2}\right), 98.1(\mathrm{C}-8), 116.3\left(\mathrm{~d}, J=21.9, \mathrm{C}-3^{\prime}, 5^{\prime}\right)$, $126.5\left(\mathrm{~d}, J=3.0, \mathrm{C}-1^{\prime}\right), 134.6(\mathrm{~d}, J=10.0$, C-2',6'), 150.5, 153.3, 157.8, 159.3, 165.7 (d, $\left.J=253.8, \mathrm{C}-4^{\prime}\right)$. MS, m/z $311.0[\mathrm{M}+\mathrm{H}]^{+}$.

2-Dichloromethyl-4-(4-fluorophenyl)-7phenylpyrazolo[1,5-a][1,3,5]triazine (3eb).
Mp $171-173{ }^{\circ} \mathrm{C}(\mathrm{MeCN}) . \mathrm{IR}, \mathrm{v}, \mathrm{cm}^{-1}:$ 3003, 1603, 1482, 1238, 1156, 1011, 845, 767, 745, 692, 662. ${ }^{1} \mathrm{H}$ NMR, $\delta, \operatorname{ppm}(J, \mathrm{~Hz}): 7.44(1 \mathrm{H}$, s, $\mathrm{H}-8$ or $\left.\mathrm{CHCl}_{2}\right), 7.48-7.58(6 \mathrm{H}, \mathrm{m}, \mathrm{H}-8$ or $\left.\mathrm{CHCl}_{2}, \mathrm{H}-3^{\prime}, 5^{\prime}, 3^{\prime \prime}-5^{\prime \prime}\right), 8.13(2 \mathrm{H}, \mathrm{d}, J=6.8$, $\left.\mathrm{H}-2^{\prime \prime}, 6^{\prime \prime}\right), 8.93-8.96\left(2 \mathrm{H}, \mathrm{m}, \mathrm{H}-2^{\prime}, 6^{\prime}\right) .{ }^{13} \mathrm{C}$ NMR, $\delta$, ppm $(J, \mathrm{~Hz}): 71.4\left(\mathrm{CHCl}_{2}\right), 95.4(\mathrm{C}-$ 8), $116.4\left(\mathrm{~d}, J=22.4, \mathrm{C}-3^{\prime}, 5^{\prime}\right), 126.5$ (d, $J=$ 2.5, C-1'), 127.4, 129.6, 130.8, 131.7, 134.8 (d, $\left.J=9.5, \mathrm{C}-2^{\prime}, 6^{\prime}\right), 151.3,153.8,158.1,159.0$, $165.8\left(\mathrm{~d}, J=253.3, \mathrm{C}-4^{\prime}\right)$. MS, m/z 373.2 $[\mathrm{M}+\mathrm{H}]^{+}$.

2-Dichloromethyl-4-(4-fluorophenyl)-7-(ptolyl)pyrazolo[1,5-a][1,3,5]triazine (3ec). Mp 210-212 ${ }^{\circ} \mathrm{C}(\mathrm{MeCN}+\mathrm{DMF}, 2: 1)$. IR, v, $\mathrm{cm}^{-1}$ : 3012, 2920, 1603, 1481, 1449, 1223, 1150, $1013,837,783,746,661 .{ }^{1} \mathrm{H}$ NMR, $\delta, \operatorname{ppm}(J$, $\mathrm{Hz}): 2.39$ (3H, s, Me-4"), 7.36-7.61 (6H, m, $\left.\mathrm{CHCl}_{2}, \mathrm{H}-8,3^{\prime}, 5^{\prime}, 3^{\prime \prime}, 5^{\prime \prime}\right), 8.06$ (2H, d, $J=8.0$, $\left.\mathrm{H}-2^{\prime \prime}, 6^{\prime \prime}\right), 8.95-8.98$ (2H, m, H-2',6'). ${ }^{13} \mathrm{C}$ NMR, $\delta, \operatorname{ppm}(J, \mathrm{~Hz}): 21.5\left(\mathrm{Me}-4^{\prime \prime}\right), 71.4$ $\left(\mathrm{CHCl}_{2}\right), 95.1(\mathrm{C}-8), 116.3(\mathrm{~d}, J=22.0$, C-3', $\left.5^{\prime}\right), 126.5\left(\mathrm{~d}, J=2.9, \mathrm{C}-1^{\prime}\right), 127.3,128.9$, $130.1,134.8\left(\mathrm{~d}, J=9.5, \mathrm{C}-2^{\prime}, 6^{\prime}\right), 140.5,151.2$, $153.5,158.0,159.1,165.7$ (d, $\left.J=253.1, \mathrm{C}-4^{\prime}\right)$. $\mathrm{MS}, \mathrm{m} / \mathrm{z} 387.2[\mathrm{M}+\mathrm{H}]^{+}$.

2-Dichloromethyl-4,7-di(4-fluorophenyl) pyrazolo[1,5-a][1,3,5]triazine (3ee). Mp 179$181^{\circ} \mathrm{C}(\mathrm{MeCN}+\mathrm{DMF}, 2: 1)$. IR, v, $\mathrm{cm}^{-1}: 3101$, 2999, 2925, 1600, 1480, 1449, 1229, 1152, 845, 789, 742, 660, 553. ${ }^{1} \mathrm{H}$ NMR, $\delta$, ppm: 7.26-7.30 (2H, m, H-3", 5"), 7.39 (2H, br. s, $\left.\mathrm{H}-8, \mathrm{CHCl}_{2}\right), 7.45-7.48$ (2H, m, H-3',5'), 8.08 $\left(2 \mathrm{H}\right.$, br. s, H-2", $\left.6^{\prime \prime}\right), 8.86-8.89(2 \mathrm{H}, \mathrm{m}$, $\left.\mathrm{H}-2^{\prime}, 6^{\prime}\right) .{ }^{13} \mathrm{C} \mathrm{NMR}, \delta, \operatorname{ppm}(J, \mathrm{~Hz}): 71.3$ $\left(\mathrm{CHCl}_{2}\right), 95.2(\mathrm{C}-8), 116.2(\mathrm{~d}, J=22.6$, C-3", $\left.5^{\prime \prime}\right), 116.4\left(\mathrm{~d}, J=22.1, \mathrm{C}-3^{\prime}, 5^{\prime}\right), 126.2(\mathrm{~d}$, $\left.J=3.0, \mathrm{C}-1^{\prime \prime}\right), 128.1\left(\mathrm{~d}, J=3.0, \mathrm{C}-1^{\prime}\right), 129.5$ (d, $J=8.5$, C-2", $\left.6^{\prime \prime}\right), 134.7$ (d, $J=9.5$, C-2', $6^{\prime}$ ), 
151.2, 153.4, 157.9, 157.9, 163.7 (d, $J=233.9$, C-4"), 165.6 (d, $J=239.9$, C-4'). MS, m/z $391.0[\mathrm{M}+\mathrm{H}]^{+}$.

4-(4-Chlorophenyl)-2-dichloromethyl-7methylpyrazolo[1,5-a][1,3,5]triazine (3fa). Mp $162-164{ }^{\circ} \mathrm{C}(\mathrm{MeCN})$. IR, v, $\mathrm{cm}^{-1}: 3000$, 1599, 1528, 1480, 1235, 1093, 1014, 842, 789, 739, 664, 531. ${ }^{1} \mathrm{H}$ NMR, $\delta$, ppm $(J, \mathrm{~Hz}): 2.52$ $(3 \mathrm{H}, \mathrm{s}, \mathrm{Me}-7), 6.81(1 \mathrm{H}, \mathrm{s}, \mathrm{H}-8), 7.39(1 \mathrm{H}, \mathrm{s}$, $\left.\mathrm{CHCl}_{2}\right), 7.74\left(2 \mathrm{H}, \mathrm{d}, J=8.0, \mathrm{H}-3^{\prime}, 5^{\prime}\right), 8.74$ $\left(2 \mathrm{H}, \mathrm{d}, J=8.0, \mathrm{H}-2^{\prime}, 6^{\prime}\right) .{ }^{13} \mathrm{C} \mathrm{NMR}, \delta$, ppm: 14.7 (Me-7), $70.9\left(\mathrm{CHCl}_{2}\right), 97.6$ (C-8), 128.3, 128.7, 132.9, 138.5, 149.9, 152.8, 157.2, 158.8 . MS, m/z $329.0[\mathrm{M}+\mathrm{H}]^{+}$.

4-(4-Chlorophenyl)-2-dichloromethyl-7phenylpyrazolo[1,5-a][1,3,5]triazine (3fb). Mp 179-181 ${ }^{\circ} \mathrm{C}(\mathrm{MeCN}) . \mathrm{IR}, v, \mathrm{~cm}^{-1}$ : 3010, 1597, 1477, 1091, 1012, 839, 768, 744, 689, 662. ${ }^{1} \mathrm{H}$ NMR, $\delta$, ppm $(J, \mathrm{~Hz}): 7.42(1 \mathrm{H}, \mathrm{s}, \mathrm{H}-8$ or $\mathrm{CHCl}_{2}$,), 7.51-7.56 (4H, m, H-8 or $\mathrm{CHCl}_{2}$, H-3"-5"), 7.79 (2H, d, $\left.J=8.4, \mathrm{H}-3^{\prime}, 5^{\prime}\right), 8.14$ $\left(2 \mathrm{H}, \mathrm{d}, J=6.8, \mathrm{H}-2^{\prime \prime}, 6^{\prime \prime}\right), 8.87(2 \mathrm{H}, \mathrm{d}, J=8.4$, $\left.\mathrm{H}-2^{\prime}, 6^{\prime}\right) .{ }^{13} \mathrm{C} \mathrm{NMR}, \delta$, ppm: $70.9\left(\mathrm{CHCl}_{2}\right), 94.9$ (C-8), 126.9, 128.3, 128.8, 129.0, 130.3, 131.1, 133.0, 138.6, 150.7, 153.3, 157.5, 158.5. MS, $\mathrm{m} / \mathrm{z} 391.0[\mathrm{M}+\mathrm{H}]^{+}$.

4-(4-Chlorophenyl)-2-dichloromethyl-7-(ptolyl)pyrazolo[1,5-a][1,3,5]triazine (3fc). Mp 197-199 ${ }^{\circ} \mathrm{C}(\mathrm{MeCN}+\mathrm{DMF}, 4: 1)$. IR, v, $\mathrm{cm}^{-1}$ : 3020, 2920, 1599, 1478, 1449, 1094, 1014, 840, 783, 744, 662. ${ }^{1} \mathrm{H}$ NMR spectrum $\left(\mathrm{CDCl}_{3}\right), \delta, \operatorname{ppm}(J, \mathrm{~Hz}): 2.42\left(3 \mathrm{H}, \mathrm{s}, \mathrm{Me}-4^{\prime \prime}\right)$, $6.73(1 \mathrm{H}, \mathrm{s}, \mathrm{H}-8), 7.01\left(1 \mathrm{H}, \mathrm{s}, \mathrm{CHCl}_{2}\right), 7.29$ $\left(2 \mathrm{H}, \mathrm{d}, J=7.8, \mathrm{H}-3^{\prime \prime}, 5^{\prime \prime}\right), 7.57-7.59$ (2H, m, H-3', $\left.5^{\prime}\right), 7.90\left(2 \mathrm{H}, \mathrm{d}, J=7.8, \mathrm{H}-2^{\prime \prime}, 6^{\prime \prime}\right), 8.99$ $\left(2 \mathrm{H}, \mathrm{d}, J=8.4, \mathrm{H}-2^{\prime}, 6^{\prime}\right) .{ }^{13} \mathrm{C}$ NMR, $\delta$, ppm: 21.0 (Me-4"), $70.9\left(\mathrm{CHCl}_{2}\right), 94.6$ (C-8), 126.7, 128.3, 128.3, 129.5, 133.0, 138.6, 140.0, 150.6, 153.0, 157.4, 158.6. MS, m/z 405.2 [M+H] $]^{+}$.
4-(4-Chlorophenyl)-2-dichloromethyl-7-(4fluorophenyl)pyrazolo[1,5-a][1,3,5]triazine (3fe). Mp 191-193 ${ }^{\circ} \mathrm{C}$ (MeCN+DMF, 2:1). IR, $v, \mathrm{~cm}^{-1}: 1605,1588,1498,1476,1449,1217$, 1158, 1090, 841, 786, 744, 662, 561. ' $\mathrm{H}$ NMR, $\delta, \operatorname{ppm}(J, \mathrm{~Hz}): 7.36-7.40\left(2 \mathrm{H}, \mathrm{m}, \mathrm{H}-3^{\prime \prime}, 5^{\prime \prime}\right)$, $7.45\left(1 \mathrm{H}, \mathrm{s}, \mathrm{H}-8\right.$ or $\left.\mathrm{CHCl}_{2}\right), 7.53(1 \mathrm{H}, \mathrm{s}, \mathrm{H}-8$ or $\left.\mathrm{CHCl}_{2}\right), 7.79\left(2 \mathrm{H}, \mathrm{d}, J=8.8, \mathrm{H}-3^{\prime}, 5^{\prime}\right), 8.18$ $8.21\left(2 \mathrm{H}, \mathrm{m}, \mathrm{H}-2^{\prime \prime}, 6^{\prime \prime}\right), 8.84(2 \mathrm{H}, \mathrm{d}, J=8.8$, $\left.\mathrm{H}-2^{\prime}, 6^{\prime}\right) .{ }^{13} \mathrm{C} \mathrm{NMR}, \delta, \operatorname{ppm}(J, \mathrm{~Hz}): 71.3$ $\left(\mathrm{CHCl}_{2}\right), 95.3(\mathrm{C}-8), 116.5(\mathrm{~d}, J=22.1$, C-3",5"), $128.2\left(\mathrm{~d}, J=3.0, \mathrm{C}-1^{\prime \prime}\right), 128.7$, $129.2,129.6\left(\mathrm{~d}, J=8.5, \mathrm{C}-2^{\prime \prime}, 6^{\prime \prime}\right), 133.5,139.1$, $151.2,153.8,158.0,158.0,163.8$ (d, $J=248.0$, $\left.\mathrm{C}-4^{\prime \prime}\right) . \mathrm{MS}, \mathrm{m} / \mathrm{z} 409.0[\mathrm{M}+\mathrm{H}]^{+}$.

4-tert-Butyl-2-dichloromethyl-7-(4-metylphenyl)pyrazolo[1,5-a][1,3,5]triazine (3gc). Mp 139-141 ${ }^{\circ} \mathrm{C}(\mathrm{MeCN})$. IR, v, $\mathrm{cm}^{-1}: 3008$, 2927, 1599, 1447, 1363, 1245, 839, 791, 748, 659. ${ }^{1} \mathrm{H}$ NMR, $\delta$, ppm $(J, \mathrm{~Hz}): 1.66(9 \mathrm{H}, \mathrm{s}$, $\left.\mathrm{Me}_{3} \mathrm{C}-4\right), 2.38\left(3 \mathrm{H}, \mathrm{s}, \mathrm{Me}-4^{\prime \prime}\right), 7.30-7.36(4 \mathrm{H}$, $\left.\mathrm{m}, \mathrm{CHCl}_{2}, \mathrm{H}-8,3^{\prime \prime}, 5^{\prime \prime}\right), 7.99(2 \mathrm{H}, \mathrm{d}, J=4.0$, $\left.\mathrm{H}-2^{\prime \prime}, 6^{\prime \prime}\right) .{ }^{13} \mathrm{C}$ NMR, $\delta$, ppm: $21.0\left(\mathrm{Me}-4^{\prime \prime}\right)$, $26.3\left(\mathrm{Me}_{3} \mathrm{C}-4\right), 38.6\left(\mathrm{Me}_{3} \mathrm{C}-4\right), 70.9\left(\mathrm{CHCl}_{2}\right)$, 94.1 (C-8), 126.7, 128.6, 129.6, 139.9, 149.8, 157.2, 157.4, 165.6. MS, m/z 349.2 [M+H] $]^{+}$.

4-tert-Butyl-2-dichloromethyl-7-(4-fluorophenyl)pyrazolo[1,5-a][1,3,5]triazine (3ge). Mp 93-95 ${ }^{\circ} \mathrm{C}$ (EtOH). IR, v, cm ${ }^{-1}: 3001,2934$, 1609, 1586, 1511, 1448, 1363, 1254, 1231, 1156, $845,791,746,659 .{ }^{1} \mathrm{H}$ NMR, $\delta$, ppm: $1.66(9 \mathrm{H}$, $\left.\mathrm{s}, \mathrm{Me}_{3} \mathrm{C}-4\right), 7.35-7.40\left(3 \mathrm{H}, \mathrm{m}, \mathrm{H}-8\right.$ or $\mathrm{CHCl}_{2}$, $\left.\mathrm{H}-3^{\prime \prime}, 5^{\prime \prime}\right), 7.45\left(1 \mathrm{H}, \mathrm{s}, \mathrm{H}-8\right.$ or $\left.\mathrm{CHCl}_{2}\right), 8.14-8.18$ $\left(2 \mathrm{H}, \mathrm{m}, \mathrm{H}-2^{\prime \prime}, 6^{\prime \prime}\right) .{ }^{13} \mathrm{C}$ NMR, $\delta, \operatorname{ppm}(J, \mathrm{~Hz})$ : $26.8\left(\mathrm{Me}_{3} \mathrm{C}-4\right), 39.1\left(\mathrm{Me}_{3} \mathrm{C}-4\right), 71.4\left(\mathrm{CHCl}_{2}\right)$, 94.8 (C-8), 116.6 (d, $\left.J=21.9, \mathrm{C}-3^{\prime \prime}, 5^{\prime \prime}\right), 128.4$ $\left(\mathrm{d}, J=3.0, \mathrm{C}-1^{\prime \prime}\right), 129.5\left(\mathrm{~d}, J=8.5, \mathrm{C}-2^{\prime \prime}, 6^{\prime \prime}\right)$, 150.4, 156.6, 158.0, 162.8, 165.4 (d, $J=247.3$, C-4"). MS, m/z $353.2[\mathrm{M}+\mathrm{H}]^{+}$. 


\section{In Vitro Anticancer Screening} of the synthesized compounds

One Doses Full NCI 60 Cell Panel Assay. The newly synthesized compounds were submitted to National Cancer Institute NCI, Bethesda, Maryland, U.S.A., under the Developmental Therapeutic Program DTP (https://dtp.cancer. gov/discovery_development/nci-60/handling. $\mathrm{htm})$. The cell line panel engaged a total of 60 different human tumor cell lines derived from nine cancer types. The selected compounds 3 were assigned with the NCI codes (see Table 1), respectively Primary in vitro one dose anticancer screening was initiated, in which the full NCI 60 panel lines were inoculated onto a series of standard 96-well microtiter plates on day 0 at $5000-40,000$ cells/well in RPMI 1640 medium containing $5 \%$ fetal bovine serum and $2 \mathrm{mM}$ L-glutamine, and then preincubated in the absence of drug at $37{ }^{\circ} \mathrm{C}$, and $5 \% \mathrm{CO}_{2}$ for $24 \mathrm{~h}$. Test compounds were then added in the same concentration of $10^{-5} \mathrm{M}$ in all 60 cell lines (drug solution preparing see in [24]), and incubated for a further $48 \mathrm{~h}$ under the same incubation conditions. Following this, the media were removed, the cells were fixed in situ, washed, and dried. The sulforhodamine B assay was used for cell density determination, based on the measurement of cellular protein content. After an incubation period, cell monolayers were fixed with $10 \%$ (wt/vol) trichloroacetic acid and stained for $30 \mathrm{~min}$, after which the excess dye was removed by washing repeatedly with $1 \%$ (vol/ vol) acetic acid. The bound stain was resolubilized in $10 \mathrm{mM}$ Tris base solution and measured spectrophotometric ally on automated microplate readers for OD determination at $510 \mathrm{~nm}$.
Five Doses Full NCI 60 Cell Panel Assay. All the 60 cell lines, representing nine cancer subpanels (Fig. 1), were incubated at five different concentrations $(0.01,0.1,1,10$ and $100 \mu \mathrm{M}$; drug solution preparing see in [23]) of the tested compounds. The outcomes were used to create $\log _{10}$ concentration versus percentage growth inhibition curves and three response parameters $\left(\mathbf{G I}_{50}\right.$, total growth inhibition (TGI) and $\mathbf{L} \mathbf{C}_{50}$ ) were calculated for each cell line. The $\mathrm{GI}_{50}$ value (growth inhibitory activity) corresponds to the concentration of the compound causing $50 \%$ decrease in net cell growth. The TGI value (cytostatic activity) is the concentration of the compound resulting in total growth inhibition. The $\mathrm{LC}_{50}$ value (cytotoxic activity) is the concentration of the compound causing net $50 \%$ loss of initial cells at the end of the incubation period of $48 \mathrm{~h}$. Data calculations were made according to the method described by the NCI Development Therapeutics Program.

COMPARE correlations were performed as described in [24]. Vectors of $\mathrm{Lg} \mathrm{GI}_{50}$ concentrations for compound 3fa (NSC 811821) were correlated with the set of corresponding average $\mathrm{GI}_{50}$ vectors from the standard agents database or all public NCI-60 vectors that contained at least 40 overlapping cell lines and had SD $>0.2$.

\section{Results and Discussion}

\section{Chemistry}

For synthesis of pyrazolo[1,5-a][1,3,5]triazines 3 we investigated different reaction conditions (at room temperature, under reflux in different solvents, with or without a base catalyst) and the most promising results were achieved when starting reagents were heated 
in tetrahydrofuran in the presence of triethylamine. Thus, it has been found that the addition of one equivalent of $1 \mathrm{H}$-pyrazol-5-amines 2 to a stirred solution of $\mathrm{N}$-(2,2-dichloro-1cyanoethenyl)carboxamides 1 in THF containing one equivalent of triethylamine under reflux gave 2-(dichloromethyl)pyrazolo[1,5-a][1,3,5] triazines 3 which were the major products of this one-pot reaction. Apparently, the heterocyclization proceeded in several stages, starting with the addition of an $\mathrm{NH}_{2}$ group to the activated $\mathrm{C}=\mathrm{C}$ bond to formed intermediate $\mathbf{A}$, followed by the elimination of hydrogen cyanide promoted by triethylamine (and intermediate $\mathbf{B}$ creation) with further intramolecular condensation into the final product 3 . Recrystallization of crude products easily yielded the pure target compounds. Our method is convenient due to mild reaction conditions, short time of the key reaction, and high degree of purity and good yields of the products.

Compounds 3 are tan solids, melting in the range of $110-210^{\circ} \mathrm{C}$, their structure was established with the help of IR, NMR spectroscopy, mass spectrometry, and X-Ray Analysis of compound 3db (CCDC1920913, deposit@ccdc.cam.ac.uk). ${ }^{1} \mathrm{H}$ NMR signal of $\mathrm{CHCl}_{2}$ and pyrazole $\mathrm{CH}$ group occurs in the region $6.7-7.5 \mathrm{ppm}$. In the spectrum of $\mathbf{3 b a}$, for example, there are two distinguished one proton singlets at 6.80 and $7.40 \mathrm{ppm}$. For other samples, one or both of these signals overlap with ArH multiplets.

\section{In Vitro Screening}

One Doses Assay. The initial assessment made it possible to identify the eight most promising structures from the collection of synthesized compounds for the one-dose assay: substances 3aa, 3ab, 3ba, 3bb, 3ca, 3fa, 3fb, 3gc. Their results are represented in Table 1.

So, the average value of the effect of the substance 3aa with two methyl substituents on the growth of cancer cells is close to $100 \%$, and the range of values is also relatively narrow, which indicates its low cytotoxicity. The anticancer properties of substance 3ab with methyl substituent in position 4 of pyrazolo[1,5a] $[1,3,5]$ triazine system and phenyl in 7 are very low too; and some growth inhibition was observed only in the case of line EKVX of non-small cell lung cancer (Table 1). tertButyl derivative 3ge also only slightly slows the growth of cancer cells.

However, the presence of aryl substituent (instead of alkyl) in position 4 leads to a swift

Table 1. The effect of the compounds $3 \mathbf{a a}, \mathbf{a b}, \mathbf{b a}, \mathbf{b b}, \mathbf{c a}, \mathbf{f a}, \mathbf{f b}, \mathbf{g c}$ on cancer cells growth according to One Doses Full NCI 60 Cell Panel Assay $\left(C=1^{-5} \mathrm{~mol} / \mathrm{L}\right)$

\begin{tabular}{l|l|l|l}
\hline \multirow{2}{*}{ Compound } & \multirow{2}{*}{ NCI code } & \multicolumn{2}{c}{ Growth Percent, \% } \\
\cline { 3 - 4 } & & \multicolumn{1}{|c}{ mean / range } & the lowermost values (cell line / panel) \\
\hline
\end{tabular}




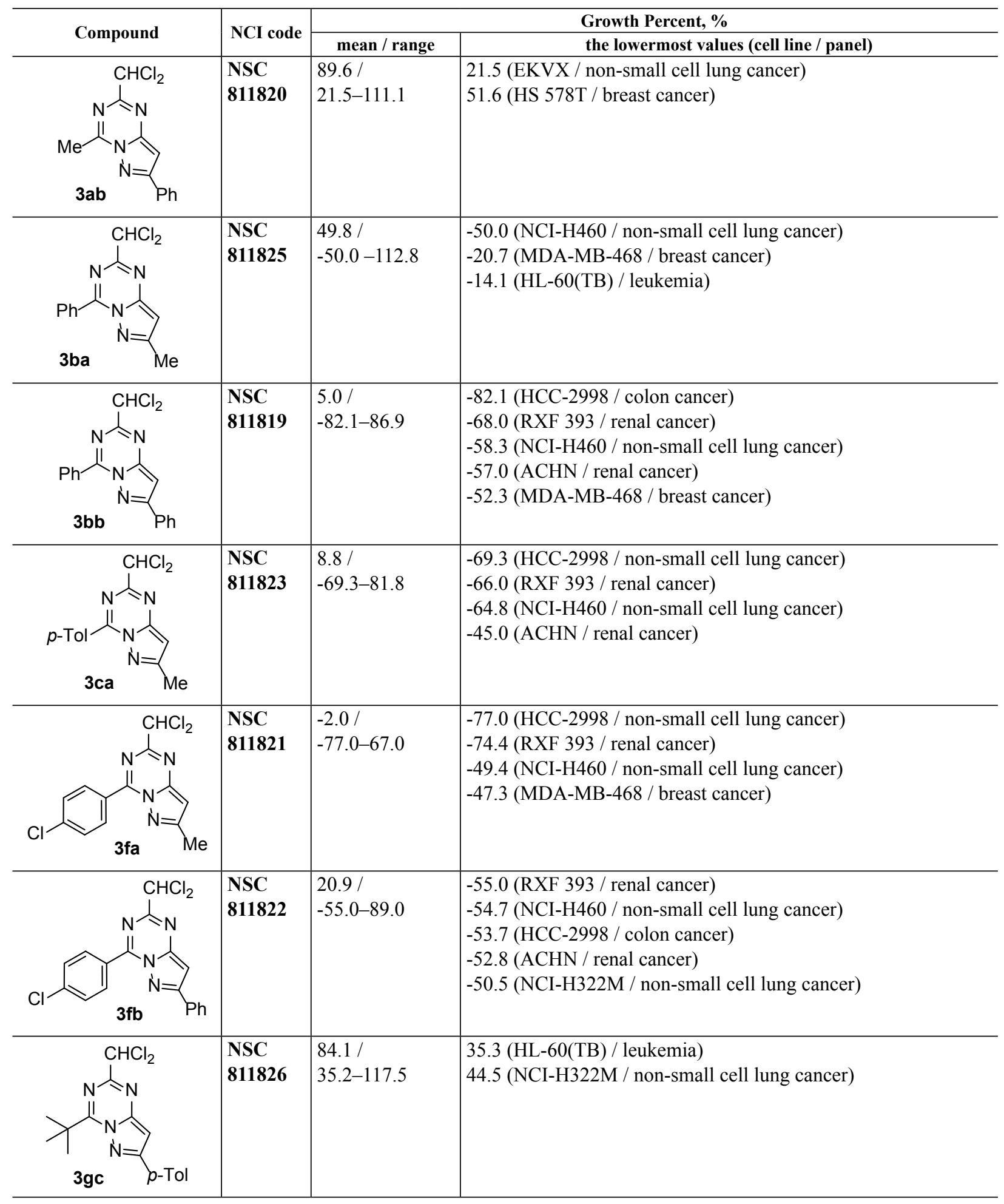


increase in activity. Substances $\mathbf{3 b a}, \mathbf{3 b b}, \mathbf{3} \mathbf{c a}$, 3fa, 3fb can effectively inhibit the growth of certain cancer cell lines. The character of the substituent in position 7 is not so important; and high cytotoxicity is inherent to the substance 3 fa with a 7-methyl group and diphenyl derivative $\mathbf{3 b b}$.

Five Doses Assay. According to the results of single dose tests, the most perspective substances $\mathbf{3 b a}, \mathbf{3 b b}, \mathbf{3 c a}, \mathbf{3 f a}, \mathbf{3 f b}$ were selected for five doses assay to establish the parameters $\mathrm{GI}_{50}$, TGI and $\mathrm{LC}_{50}$. In Table 2 the mean values of these parameters are given, as well as their values for the cell lines referred in Table 1.

Substances $\mathbf{3 b a}, \mathbf{3 b b}, \mathbf{3 c a}, \mathbf{3 f a}, \mathbf{3 f b}$ displayed significant growth inhibition effect on cell lines besides those given in Tables 1, 2, as generalized dose response curves demonstrate (Fig. 1).

\section{NCI 60 Cell Panel COMPARE} Correlations

COMPARE analysis [24] was performed to propose a mechanism of action of the investigated compounds. Only for compound 3fa (NSC 811821) the correlation, computed as the $\mathrm{GI}_{50}$ vector, exceeded 0.5 in comparison with Fluorouracil. This antineoplastic agent produces active metabolites that incorporate into RNA and DNA and inhibit their processing, thereby inhibiting cell growth [25]. For other investigated compounds (3ba, bb, $\mathbf{c a}, \mathbf{f b})$ no analogues of anticancer mechanism were found, therefore 4-(dichloromethyl)pyrazolo[1,5-a][1,3,5]triazine derivatives could potentially be a new class of anticancer agents.

\section{Conclusions}

By starting from $N$-(2,2-dichloro-1-cyanoethenyl)carboxamides 1 and 1H-pyrazol-5-

Table 2. The Five Doses Full NCI 60 Cell Panel Assay of the compounds 3ba, bb, ca, fa, fb (the concentrations $\mathrm{GI}_{50}$, TGI and $\mathrm{LC}_{50}, \mathrm{~mol} / \mathrm{L}$, given as $\mathrm{lg}$ )

\begin{tabular}{|c|c|c|c|c|c|}
\hline \multirow{2}{*}{\multicolumn{2}{|c|}{ Compound / parameter }} & \multirow{3}{*}{\begin{tabular}{|c|}
$\begin{array}{c}\text { Mean value NCI-H460 / } \\
\text { non-small cell lung cancer }\end{array}$ \\
-5.35
\end{tabular}} & \multicolumn{3}{|c|}{ Value of certain cancer cell lines' growth inhibition } \\
\hline & & & \multirow{2}{*}{$\begin{array}{c}\begin{array}{c}\text { HCC-2998 / colon } \\
\text { cancer }\end{array} \\
-5.71\end{array}$} & \multirow{2}{*}{$\begin{array}{c}\mathbf{R X F} \mathbf{3 9 3} / \text { renal } \\
\text { cancer } \\
-5.75\end{array}$} & \multirow[b]{2}{*}{-5.64} \\
\hline \multirow{3}{*}{$\begin{array}{l}\text { 3ba } \\
\text { (NSC } \\
811825)\end{array}$} & $\lg \mathrm{GI}_{50}$ & & & & \\
\hline & $\lg$ TGI & -4.63 & -5.29 & -5.46 & -5.24 \\
\hline & $\lg L_{50}$ & -4.12 & $>-4.00$ & -5.16 & -4.65 \\
\hline \multirow{3}{*}{$\begin{array}{l}\mathbf{3 b b} \\
(\mathrm{NSC} \\
811819)\end{array}$} & $\lg \mathrm{GI}_{50}$ & -5.65 & -6.39 & -6.24 & -6.27 \\
\hline & $\lg$ TGI & -4.88 & -5.73 & -5.69 & -5.62 \\
\hline & $\lg L_{50}$ & -4.18 & -5.10 & -5.28 & -5.13 \\
\hline \multirow{3}{*}{$\begin{array}{l}\text { 3ca } \\
(\mathrm{NSC} \\
811823)\end{array}$} & $\lg \mathrm{GI}_{50}$ & -5.68 & -6.29 & -5.93 & -6.17 \\
\hline & $\lg$ TGI & -4.68 & -5.52 & -5.59 & -5.63 \\
\hline & $\lg L_{50}$ & -4.13 & -4.12 & -5.25 & -5.20 \\
\hline \multirow{3}{*}{$\begin{array}{l}\text { 3fa } \\
\text { (NSC } \\
811821) \\
\end{array}$} & $\lg \mathrm{GI}_{50}$ & -6.04 & -6.52 & -6.21 & -6.29 \\
\hline & $\lg$ TGI & -5.3 & -5.97 & -5.67 & -5.70 \\
\hline & $\lg L_{50}$ & -4.25 & $>-4.00$ & -5.24 & -5.27 \\
\hline \multirow{3}{*}{$\begin{array}{l}\mathbf{3 f b} \\
(\mathrm{NSC} \\
811822)\end{array}$} & $\lg \mathrm{GI}_{50}$ & -5.69 & -6.10 & -6.13 & -6.09 \\
\hline & $\lg$ TGI & $\begin{array}{l}-4.71 \\
\end{array}$ & -5.67 & -5.85 & -5.73 \\
\hline & $\lg \mathrm{LC}_{50}$ & -4.36 & $>-4.30$ & -5.56 & -5.37 \\
\hline
\end{tabular}



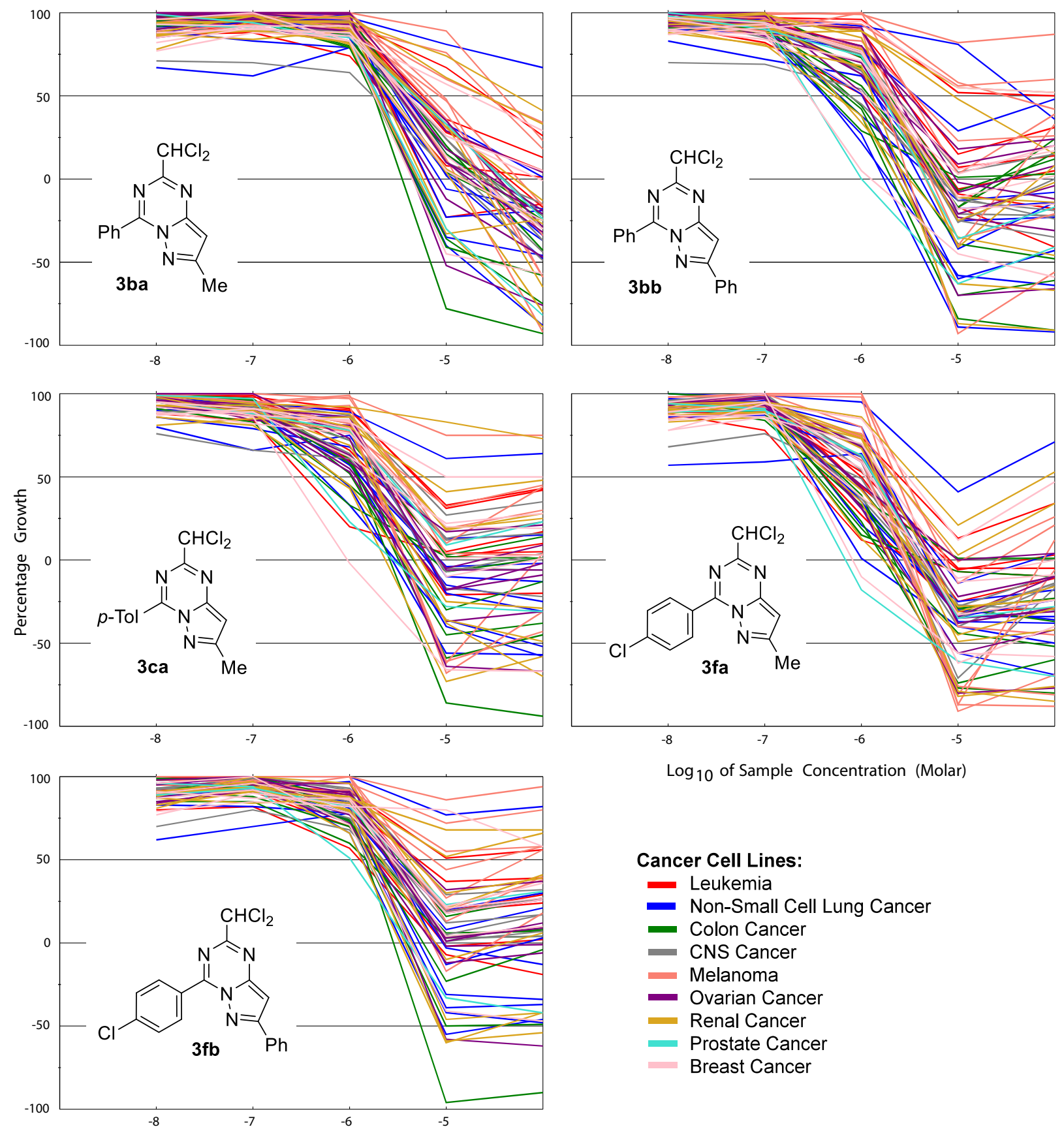

Fig. 1. Five Dose Data Graphs for compounds $\mathbf{3 b a}, \mathbf{b b}, \mathbf{c a}, \mathbf{f a}, \mathbf{f b} \log _{10} \mathrm{C}(\mathrm{C}-$ compound concentration, $\mathrm{mol} / \mathrm{L}) /$ cancer cells percentage growth, $\%$ 
amines 2, 26 new 4(dichloromethyl) pyrazolo[ $[1,5-a][1,3,5]$ triazine derivatives with expected biological activity were synthesized. Compounds 3ba, 3bb, 3ca, 3fa, 3fb with an aromatic substituent in position 4 can effectively inhibit the growth of certain cancer cell lines, whereas compounds with an alkyl substituent in the same position possess low cytotoxicity. Future work will be focused on the improvement of their biophysical properties to yield drug-like pre-clinical candidates for in vivo animal studies. COMPARE analysis did not reveal any known anticancer drugs with a similar action, which warrants a more detailed study of the anticancer action mechanism of the obtained 4(dichloromethyl)pyrazolo[1,5- $a]$ $[1,3,5]$ triazine.

\section{Acknowledgements}

We would like to thank US Public Health Service and National Cancer Institute, USA, for in vitro evaluation of anticancer activity (providing the NCI-60 cell testing) within the framework of Developmental Therapeutic Program (http://dtp.cancer.gov), and Enamine Ltd for the material and technical support.

\section{Disclaimer}

This material should not be interpreted as representing the viewpoint of the U.S. Department of Health and Human Services, the National Institutes of Health, or the National Cancer Institute.

\section{REFERENCE}

1. Schreiber SL. Target-oriented and diversity-oriented organic synthesis in drug discovery. Science. 2000; 287(5460): 1964-9.
2. Popowycz F, Fournet G, Schneider C, Bettayeb K, Ferandin $Y$, Lamigeon C, Tirado OM, MateoLozano S, Notario V, Colas P, Bernard Ph, Meijer L, Joseph B. Pyrazolo[1,5-a]-1,3,5-triazine as a purine bioisostere: access to potent cycline-dependent kinase inhibitor (R)-roscovitine analogue. $\mathrm{J} \mathrm{Med}$ Chem. 2009; 52(3): 655-63.

3. He L, Gilligan PJ, Zaczek R, Fitzgerald LW, McElroy $J$, Shen $H L$, Saye JA, Kalin $N H$, Shelton $S$, Christ D, Trainor G, Hartig P. 4-(1,3-Dimethoxyprop-2-ylamino)-2,7-dimethyl-8-(2,4-dichlorophenyl)pyrazolo[1,5-a]-1,3,5-triazine: a potent, orally bioavailable CRF1 receptor antagonist. J Med Chem. 2000; 43(3): 449-56.

4. Nie Zh, Perreta C, Erickson Ph, Margosiak S, Almassy R, Lu J, Averill A, Yager K, Chu Sh. Structurebased de-sign, synthesis, and study of pyrazolo[1,5a] $[1,3,5$, ]triazine derivatives as potent inhibitors of protein kinase CK2. Bioorg Med Chem Lett. 2007; 17(15): 4191-5.

5. Nie Zh, Perreta C, Erickson Ph, Margosiak S, Lu J, Averill A, Almassy R, Chu Sh. Structure-based design and synthesis of novel pyrazolo[1,5-a][1,3,5] triazine compounds as potent inhibitors of protein kinase CK2 and their anticancer activities. Bioorg Med Chem Lett. 2008; 18(2): 619-23.

6. Ali Tel-S. Synthesis of some novel pyrazolo[3,4-b] pyridine and pyrazolo[3,4-d]pyrimidine derivatives bearing 5,6-diohenyl-1,2,4-triazine moiety as potential antimicrobial agents. Eur J Med Chem. 2009; 44(11): 4385-92.

7. Rooney CS, Williams HWR. Pyrazolo [1,5-a] [1,3,5] triazines. US Patent US3995039A. 1976.

8. Popowycz F, Schneider C, Debonis S, Skoufias DA, Kozielski F, Galmarini CM, Joseph B. Synthesis and antipro-liferative evaluation of pyrazolo[1,5-a]1,3,5-triazine myoseverin derivatives. Bioorg Med Chem. 2009; 17(9): 3471-8.

9. Shaabani A, Nazeri MT, Afshari R. 5-Amino-pyrazoles: potent reagents in organic and medicinal synthesis. Mol Div. 2018; 22(1): 1-57.

10. Matsumura K, Saraie T, Hashimoto N. $\beta \beta$-Dichloro$\alpha$-aminoacrylonitrile. J Chem Soc Chem Commun. 1972; 1(12): 705-6. 
11. Drach BS, Sviridov EP, Kisilenko AA, Kirsanov AV. Interaction of secondary amines with N-acyl-2,2dichlorovinylamines and $\mathrm{N}$-acyl-1-cyano-2,2-dichlorovinylamines. J Org Chem USSR. 1973; 9: 1842-6.

12. Matsumura K, Saraie T, Hashimoto N. Studies of nitriles. VIII. Reactions of $\mathrm{N}$-acyl derivatives of 2-amino-3,3-dichloroacrylonitrile (ADAN) with amines. 1. A new synthesis of 2-substituted5-(substituted ami-no)oxazole-4-carbonitriles and 4-N-acylcarboxamides. Chem Pharm Bull. 1976; 24(5): 924-40.

13. Chumachenko SA, Shablykin OV, Vasilenko AN, Brovarets VS. Synthesis and some properties of 5-alkylamino-2-(phthalimidoalkyl)-1,3-oxazole4-carbonitriles. Chem Heterocycl Comp. 2011; 47(8): 1020-8.

14. Abdurahmanova ER, Lukashuk EI, Golovchenko AV, Pil'o SG, Brovarets VS. N-Methyl-D-glucamineDerived 4-Substituted 1,3-Oxazoles. Rus. J. Gen. Chem. (Engl. Transl.) 2015; 85(4): 851-7.

15. Vinogradova TK, Mis'kevich GN, Drach BS. Reaction of functional derivatives of 3,3-dichloro-2-acylaminoacrylic acids with benzamidine. J Org Chem USSR. 1980; 16: 1587-92.

16. Chumachenko SA, Shablykin OV, Kozachenko AP, Osadchuk TV, Brovarets VS. A new route for the synthesis of substituted 5-amino-4-cyanoimidazol2-ones - precursors for the preparation of 3,6,7,9-tetrahydro-8H-purin-8-ones derivatives. Chem Heterocycl Comp. 2011; 47(3): 336-41.

17. Kozachenko AP, Shablykin OV, Rusanov EB, Vasilenko AN, Brovarets VS. Transformation of the condensation products of 2-acylamino-3,3-dichloroacrylonitriles with imidazole into pyrazolo- $[1,5-\mathrm{a}]$ pyrimidine derivatives. Rus J Gen Chem. 2009; 79(5): 996-1000.

18. Kozachenko AP, Shablykin OV, Chernega AN, Brovarets VS. Synthesis of a new heterocyclic system 7,8-dihydroimidazo[1,2-c][1,3]oxazolo[4,5-e]pyrimidine. Chem Heterocycl Comp. 2010; 46(9): 1116-21.

19. Kozachenko AP, Shablykin OV, Vasilenko AN, Chernega AN, Brovarets VS. Synthesis and structure of a new heterocyclic system - 7,8-dihydroimida- zo[1,2-c][1,3]thiazolo[4,5-e]pyrimidine. Chem Hetегосусl Сотрю 2011; 47(4): 507-11.

20. Kozachenko AP, Shablykin OV, Gakh AA, Rusanov EB, Brovarets VS. Synthesis of new heterocyclic system of 4,5,7,8-tetrahydroimidazo[1,2-c] $[1,3]$ thiazolo[4,5-e][1,3,2]diazaphosphinine starting from 2-aroylamino-3,3-dichloroacrylonitrile. Heteroatom Chem. 2010; 21(7): 492-8.

21. Shablykin OV, Gakh AA, Brovarets VS, Rusanov EB, Drach $B S$. A Facile Synthesis of New 1,2-Dihydro$2 \lambda 5$-[1,3]oxazolo[5,4-d][1,3,2]diazaphosphinine Derivatives Starting from 2-Benzoylamino-3,3-dichloroacrylonitrile. Heteroatom Chem. 2008; 19(5): 506511.

22. Velihina YeS, Pil'o SG, Zyabrev VS, Brovarets VS. Synthesis and antiviral activity of 2-(dichloromethyl)pyrazolo[1,5-a][1,3,5]triazines. Dopov Nac akad nauk Ukr. 2019; (7): 75-80.

23. Zyabrev VS, Babiy SB, Turov KV, Vasilenko OM, Vinogradova TK, Brovarets VS. 2,4-Disulfanyl5-cycloamino substituted thiazoles and their using as anticancer drugs (in Ukrainian). Patent 109165 UA. 2015.

24. Boyd MR, Paull KD. Some practical considerations and applications of the national cancer institute in vitro anti-cancer drug discovery screen. Drug Dev Res. 1995; 34: 91-109.

25. Longley DB, Harkin DP, Johnston PG. 5-Fluorouracil: mechanisms of action and clinical strategies. Nat Rev Cancer. 2003; 3: 330-8.

\section{2-(Дихлорометил)піразоло[1,5-a][1,3,5]} триазини: синтез та протиракова активність
Е. С. Велігіна, С. Г. Пільо, В. С. Зябрев,
В. С. Москвіна, О. В. Шабликіна, В. С. Броварець

Мета. Синтез серії 2-(дихлорометил)піразоло[1,5-a] $[1,3,5]$ триазинів та дослідження in vitro їх протиракової активності на панелі з 60 клітинних ліній, отриманих від дев'яти типів раку, а саме лейкемії, недрібноклітинний рак легенів, рак товстої кишки, рак ЦНС, меланома, рак яєчників, рак нирок, рак простати, рак молочної залози. Методи. Органічний синтез; біологічні тести; спектральні методи; статистичні методи. Результати. Проведення in vitro скринінгу протирако- 
вої активності показало, що 5 з 26 досліджуваних сполук можуть ефективно пригнічувати ріст певних ракових клітинних ліній. Висновки. Новий тип гетероциклізації $N$-(2,2-дихлоро-1-ціаноетил)карбоксамідів з $1 H$-піразол-5-амінами привела до отримання 2-(дихлорометил)піразоло[1,5- $a][1,3,5]$ триазинів. Деякі 3 отриманих сполук пригнічують ріст певних ракових клітин.

Кл юч о в і с л о в а: in vitro скринінг, протиракова активність, гетероциклізація, $1 H$-піразол-5-аміни, піразоло[1,5-a][1,3,5]триазини, 2-(дихлорометил) піразоло[1,5- $a][1,3,5]$ триазини.

\section{2-(Дихлорометил)пиразоло[1,5-a][1,3,5] триазины: синтез и противораковая активность}

Е. С. Велигина, С. Г. Пильо, В. С. Зябрев, В. С. Москвина, О. В. Шаблыкина, В. С. Броварец

Цель. Синтез серии 2-(дихлорометил)пиразоло[1,5- $a]$ $[1,3,5]$ триазинов и исследование их противораковой активности in vitro на панели из 60 клеточных линий, полученных из 9 типов рака, а именно лейкемии, немелкоклеточный рак легких, рак толстой кишки, рак ЦНС, меланома, рак яичников, рак почек, рак простаты, рак молочной железы. Методы. Органический синтез; биологические тесты; спектральные методы; статистические методы. Результаты. Скриниг противораковой активности in vitro показал, что 5 из 26 исследуемых соединений могут эффективно ингибировать рост определенных линий раковых клеток. Выводы. Новий тип гетероциклизации $N$-(2,2-дихлоро1 -цианоэтил)карбоксамидов и $1 H$-пиразол-5-аминов привел к получению 2-(дихлорометил)пиразоло[1,5- $a$ ] $[1,3,5]$ триазинов. Некоторые из полученных соединений ингибируют рост определенных линий раковых клеток.

К л юч е в ы е с л о в а: in vitro скрининг, протираковая активность, гетероциклизация, $1 H$-пиразол-5-амины, пиразоло[1,5- $a][1,3,5]$ триазины, 2-(дихлорометил)пиразоло[1,5- $a][1,3,5]$ триазины. 